\title{
An Investigation of Freshmen' Attitudes Toward Their Native and Nonnative English Teachers
}

\author{
ZHOU Dan \\ School of Foreign Languages, \\ Wuhan Textile University \\ Wuhan, China \\ E-mail:Windy_zhou@163.com
}

\author{
HOU Lulu \\ School of Foreign Languages, \\ Huazhong University of Science and Technology \\ Wuhan, China \\ E-mail:houlululaura@163.com
}

\begin{abstract}
With the advancement of globalization, more qualified English teachers are needed in the field of ELT. The different roles of native speakers and nonnative speakers in EFL and ESL teaching and particulars to the issue of the dichotomy of native-English-speaking teachers (NESTs) and Nonnative-English-speaking teachers (NNESTs) have been focused on by many researchers and scholars. This paper is an attempt to find out EFL freshmen' attitudes towards their NESTs and NNESTs and the correlations between the freshmen's' evaluation of the specific teaching features and their satisfaction towards these two camps of teachers. The findings of the study are expected to better understand these two camps of teachers and exert their teaching potential.
\end{abstract}

Keywords-freshmen'attitudes, native-English-speaking teacher nonnative-English-speaking teacher (NNEST)

(NEST),

\section{INTRODUCTION}

According to statistics from Education Ministry of China, there are more than eight million EFL freshmen, almost 60 thousand English teachers in Chinese universities in the year of 2013. Meanwhile, the number of NESTs is also considerable and grows fast with China's increasing contact with the outside world. How to further develop their teaching effectiveness and efficiency within their own constraints is a question confronting us. The present research study aims to confirm NNESTs' strengths in English teaching profession through quantitative and qualitative research of the freshmen' attitude to these two camps of teachers so as to reiterate that NNESTs have an equal chance of professional success (Medgyes, 1992). Moreover, the purpose of this research also lies in providing suggestions on course assignment for these two camps of teachers and improving understanding and communication between teachers and freshmen in order to enhance teaching efficiency and effectiveness eventually.

\section{IILITERATURE REVIEW}

According to the Oxford Companion to the English language a "native speaker" refers to "a person who has spoken a certain language since early childhood"
(Christophersen \& McArthur, 1992). Many researchers and scholars have redefined the tern of a "native speaker". Kramsch's (1995) second definition of a native speaker is that it is a question of birth privilege. This idea is corroborated by the Belgian linguist Rene Copieters (1987), who assents that a native speaker of English is someone "who is accepted as such by the community". Based on the previous studies, Nayar (1994) points out that some of the features, such as primacy in order of acquisition, dominance, frequency and comfort of use and other-perception of linguistic membership and eligibility, have primacy over others when deciding who is a "perfect" native speaker.

In brief, a NEST refers to one who has grown up in the countries that claim the ownership of English. A NS is not necessarily a typical white Anglo-Americans. However, in the present paper, the term NESTs refers to foreign English teachers due to the fact that most of the foreign teachers are regarded as the "language experts".

\section{III.DESIGNS AND IMPLEMENTATION}

In June 2014, 100 college freshmen, including freshmen and sophomores, majoring in English from Wuhan Textile University responded to the questionnaire. The questionnaire for the present survey is to investigate Chinese EFL college freshmen' expectation of course assignment for NESTs and NNESTs, and their evaluation of both camps of teachers in terms of linguistic proficiency, cultural knowledge and pedagogy. Written in Chinese, it consists of two parts: The first part surveys freshmen' expectation of course assignment for NESTs and NNESTs. The second part asks the freshmen to evaluate their NESTs and NNESTs concerning their linguistic competence (from Item 1 to Item 4), cultural knowledge (Item 5), teaching practice (from Item 6 to 16), and their satisfaction with NESTS and NNESTs (Item 17). A five-point scale was adopted, so the higher marks a student gives, the more he is satisfied with that item. The questionnaire is designed according to Medyes' study of the strengths of NNESTs (Medyes, 2002), Phillipson's description of the strong points of NESTs (Phillipson, 2006), and Duan and Deng's (2012) survey of EFL freshmen' preference of the courses taught by NESTS or NNESTs and evaluation of NESTs and NNESTs on their teaching roles and features.

All the questionnaires were collected within the set 
time. The return rate and validity are both 100 percent. The collected data are processed with SPSS. Correlation coefficient analysis was performed to find out the correlations between specific teaching features of each camp of teachers and the subjects' satisfaction. Finally, reliability is calculated to examine whether the instrument of this survey is stable and trustworthy.

\section{RESULTS}

\section{A. The subjects' expectation of course assignment}

The first question in course assignment is what courses are offered by NESTs. All of the subjects have taken oral English classes taught by NESTS, and 69 subjects have attended NESTs' writing lessons.

The second and the third questions are what courses are expected to be taught by NESTs and by NNESTs. Most of the subjects expect a NEST to teach oral English, pronunciation, American and British cultures and listening. In specific, 100 percent of the subjects expect a NEST to teach oral English with 99 of them in favor of a NEST and none preferring the opposite. As for the courses of pronunciation, cultures of English speaking countries and listening, there are 97 percent, 65 percent and 56 percent of the subjects expecting a NEST respectively. Some subjects are unsure of or miss choosing the item, so the number of the subjects who expect a NEST for a certain course plus the number desiring for a NNEST is not equal to one hundred. According to the subjects, the courses expected to be offered by NNESTs are intensive reading (97 percent of the subjects prefer a NNEST), grammar (90 percent), linguistics (88 percent), extensive reading (87 percent), translation (87 percent), American and British literatures (69 percent), and writing (55 percent).

$B$. The subjects 'evaluation of their NESTs and NNESTs

- The subjects' evaluation of specific teaching features

The subjects' evaluation of specific teaching features of each camp of teachers is listed in Table 1. Means and standard deviations are calculated. As for the items of linguistic proficiency and cultural knowledge, as expected, NESTs perform better than NNESTs, especially in the aspects of pronunciation and fluency. However, except creating an active class atmosphere, NNESTs are better viewed in all the other items-languages and cultures comparison, grammar explanation, knowing freshmen' English level, difficulties and needs, predicting their problems in learning English, teaching learning strategy, class preparation and management. The Chinese language is considered much more useful in NNESTs' classroom. Both camps of teachers are willing to help their freshmen, while NNESTs receive a relatively higher evaluation in this aspect. In general, the subjects are more satisfied with NNESTs' teaching.

Standard deviations show that the subjects' evaluation of NESTS varies more significantly than that of NNESTs, especially in class preparation and management items.
TABLE 1

THE SUBJECTS' EVALUATION OF NESTS AND NNESTS ON THEIR TEACHING FEATURES

\begin{tabular}{|c|c|c|c|c|}
\hline \multirow[b]{2}{*}{ Teaching Features } & \multicolumn{2}{|c|}{ Evaluation of NESTs } & \multicolumn{2}{|c|}{$\begin{array}{c}\text { Evaluation of } \\
\text { NNESTs } \\
\end{array}$} \\
\hline & Mean & $\begin{array}{c}\text { Std. } \\
\text { Deviation }\end{array}$ & Mean & $\begin{array}{c}\text { Std. } \\
\text { Deviati } \\
\text { on }\end{array}$ \\
\hline Standard pronunciation & 4.32 & .618 & 3.51 & .628 \\
\hline Fluent expression & 4.80 & .426 & 3.93 & .700 \\
\hline $\begin{array}{l}\text { Assessing a correct } \\
\text { language form }\end{array}$ & 3.92 & .918 & 3.73 & .633 \\
\hline $\begin{array}{c}\text { Understanding idiomatic } \\
\text { expressions }\end{array}$ & 4.05 & .892 & 3.67 & .779 \\
\hline $\begin{array}{l}\text { Familiar with cultural } \\
\text { knowledge }\end{array}$ & 4.26 & .705 & 3.72 & .712 \\
\hline $\begin{array}{l}\text { Comparing the two } \\
\text { languages \& cultures }\end{array}$ & 3.10 & 1.020 & 3.89 & .601 \\
\hline Explaining grammar & 3.24 & .854 & 4.24 & .622 \\
\hline Using mother tongue & 2.28 & 1.111 & 4.14 & .888 \\
\hline $\begin{array}{l}\text { Creating an active class } \\
\text { atmosphere }\end{array}$ & 4.09 & .965 & 3.03 & .771 \\
\hline $\begin{array}{l}\text { Knowing freshmen' English } \\
\text { level }\end{array}$ & 3.21 & .924 & 3.78 & .733 \\
\hline $\begin{array}{l}\text { Knowing freshmen' } \\
\text { difficulties \& needs }\end{array}$ & 3.21 & 1.028 & 3.82 & .757 \\
\hline $\begin{array}{c}\text { Predicting freshmen' } \\
\text { problems } \\
\end{array}$ & 2.98 & .953 & 3.74 & .760 \\
\hline Teaching learning strategies & 3.10 & .980 & 3.72 & .830 \\
\hline Willing to help freshmen & 4.24 & 1.006 & 4.48 & .627 \\
\hline Preparing class well & 3.71 & 1.122 & 4.46 & .626 \\
\hline Managing class efficiently & 3.48 & 1.243 & 4.48 & .594 \\
\hline Overall evaluation & 3.63 & .991 & 3.83 & .697 \\
\hline
\end{tabular}

Correlations between the teaching features and the subjects' satisfaction

This part presents a general description and comparison among and within the different aspects of teaching practice including linguistic proficiency, cultural knowledge and pedagogy.

As Table 2 shows, in the aspect of linguistic proficiency, pronunciation has the strongest impact on the subjects' satisfaction in all the four items listed in linguistic proficiency. Assessing acceptability also has relatively strong effect on the subjects' satisfaction with a correlation of .414. Fluency and idiomatic expression understanding of NESTs' relate to the subjects' satisfaction insignificantly.

Similarly, pronunciation of NNESTs is more influential on the subjects' satisfaction than other items in linguistic proficiency with a moderate correlation of 0.425 . Statistically, no strong relationships are showed between the subjects' satisfaction and the other three items including NNESTs' fluency in expression, understanding idiomatic expressions and assessing correctness of given language forms.

Cultural knowledge seems to weakly link to the 
subjects' satisfaction with NESTs as well as with NNESTs, which shows the influence of EFL teachers' cultural familiarity on the subjects' satisfaction is unimportant.

In pedagogy, helpfulness of using the Chinese language slightly links to subjects' satisfaction with both camps of teachers, with correlations of .198 and .352. Similarly, the ability to compare the two languages and cultures has a neglectable effect on freshmen' satisfaction with NESTs as well as with NNESTs.

Some of the items in pedagogy have relatively strong impacts on the subjects' satisfaction with both camps of EFL teachers among which knowing freshmen' difficulties and needs is more influential in determining the subjects' satisfaction with NESTs as illustrated by a strong correlation of .621.

Surprisingly, other teaching features have different effects on the subjects' satisfaction with NESTs and NNESTs. Though grammar explanation has a weak correlation with the subjects' satisfaction with NESTs, it has the strongest impact on the subjects' satisfaction with NNESTs among all the items listed with a correlation of .540. In sharp contrast, willingness to help freshmen, class preparation and management are closely related to the subjects' satisfaction with NESTs but not with NNESTs. Although both NESTs and NNESTs are willing to help their freshmen according to the subjects, the subjects' satisfaction is more positively influenced by NESTs' performance in this respect. Similarly, the subjects only demonstrate great sensitivity to NESTs' class preparation and management as shown by correlations of .745 and .739, the strongest among all the correlations.

TABLE 2

CORRELATIONS BETWEEN SPECIFIC TEACHING FEATURES AND THE

\begin{tabular}{|c|c|c|c|}
\hline \multicolumn{4}{|c|}{ SUBJECTS' SATISFACTION } \\
\hline $\begin{array}{l}\text { Teaching } \\
\text { Features }\end{array}$ & \multicolumn{2}{|c|}{ Satisfaction with NESTs } & $\begin{array}{l}\text { Satisfaction with } \\
\text { NNESTs }\end{array}$ \\
\hline \multirow{2}{*}{$\begin{array}{c}\text { Standard } \\
\text { pronunciation }\end{array}$} & Correlation & $.512(* *)$ & $.425(* *)$ \\
\hline & Sig. & .000 & .000 \\
\hline \multirow{2}{*}{$\begin{array}{c}\text { Fluent } \\
\text { expression }\end{array}$} & Correlation & $.362(* *)$ & $.371(* *)$ \\
\hline & Sig. & .000 & .000 \\
\hline \multirow{2}{*}{$\begin{array}{c}\text { Assessing a } \\
\text { correct } \\
\text { language form }\end{array}$} & Correlation & $.414(* *)$ & $.312(* *)$ \\
\hline & Sig. & .000 & .002 \\
\hline \multirow{2}{*}{$\begin{array}{l}\text { Understanding } \\
\text { idiomatic } \\
\text { expressions }\end{array}$} & Correlation & $.385(* *)$ & $.359(* *)$ \\
\hline & Sig. & .000 & .000 \\
\hline \multirow{2}{*}{$\begin{array}{l}\text { Familiar with } \\
\text { cultural } \\
\text { knowledge }\end{array}$} & Correlation & $.253(*)$ & $.221(*)$ \\
\hline & Sig. & .011 & .027 \\
\hline \multirow{2}{*}{$\begin{array}{l}\text { Comparing the } \\
\text { two languages } \\
\text { \& cultures }\end{array}$} & Correlation & $.270(* *)$ & $.279(* *)$ \\
\hline & Sig. & .000 & .005 \\
\hline \multirow{2}{*}{$\begin{array}{c}\text { Explaining } \\
\text { grammar }\end{array}$} & Correlation & $.342(* *)$ & $.540(* *)$ \\
\hline & Sig. & .000 & .000 \\
\hline \multirow{2}{*}{$\begin{array}{l}\text { Using mother } \\
\text { tongue }\end{array}$} & Correlation & $.198(*)$ & $.353(* *)$ \\
\hline & Sig. & .020 & .004 \\
\hline \multirow{2}{*}{$\begin{array}{l}\text { Creating an } \\
\text { active class } \\
\text { atmosphere }\end{array}$} & Correlation & $.478(* *)$ & $.432(* *)$ \\
\hline & Sig. & .000 & .000 \\
\hline
\end{tabular}

\begin{tabular}{|c|c|c|c|}
\hline \multirow{2}{*}{$\begin{array}{c}\text { Knowing } \\
\text { freshmen' } \\
\text { English level } \\
\end{array}$} & Correlation & $.453(* *)$ & $.436(* *)$ \\
\hline & Sig. & .000 & .000 \\
\hline \multirow{2}{*}{$\begin{array}{c}\text { Knowing } \\
\text { freshmen' } \\
\text { difficulties \& } \\
\text { needs } \\
\end{array}$} & Correlation & $.621(* *)$ & $.393(* *)$ \\
\hline & Sig. & .000 & .000 \\
\hline \multirow{2}{*}{$\begin{array}{l}\text { Predicting } \\
\text { freshmen' } \\
\text { problems }\end{array}$} & Correlation & $.580(* *)$ & $.493(* *)$ \\
\hline & Sig. & .000 & .000 \\
\hline \multirow{2}{*}{$\begin{array}{c}\text { Teaching } \\
\text { learning } \\
\text { strategies }\end{array}$} & Correlation & $.490(* *)$ & $.462(* *)$ \\
\hline & Sig. & .000 & .000 \\
\hline \multirow{2}{*}{$\begin{array}{l}\text { Willing to help } \\
\text { freshmen }\end{array}$} & Correlation & $.599(* *)$ & $.276(* *)$ \\
\hline & Sig. & .000 & .000 \\
\hline \multirow{2}{*}{$\begin{array}{c}\text { Preparing class } \\
\text { well }\end{array}$} & Correlation & $.745(* *)$ & $.357(* *)$ \\
\hline & Sig. & .000 & .000 \\
\hline \multirow{2}{*}{$\begin{array}{c}\text { Managing } \\
\text { class } \\
\text { efficiently }\end{array}$} & Correlation & $.739(* *)$ & $.378(* *)$ \\
\hline & Sig. & .000 & .000 \\
\hline
\end{tabular}

\section{SUGGESTIONS AND IMPLICATIONS}

Based on the findings of the present study, suggestions for NESTs and NNESTs further development are put forward in three aspects: linguistic proficiency, cultural knowledge and pedagogy.

\section{A. Linguistic Proficiency}

The findings of the present study confirm that NESTs have the advantage of achieving linguistic proficiency over their counterpart in various aspects such as pronunciation and fluency. On one hand, they can enhance their language skills with the help of native speakers by frequent contact with them. On the other hand, various media and high technology also offer NNESTs ample opportunities to get access to the English language.

B. Cultural Knowledge

NNESTs should make the best use of the their contacts with NESTs by hearing their personal description and explanation about their own cultures, observing the differences between Chinese and Western cultures. Moreover, many other ways are also feasible for NNESTs to become more familiar with the target cultures. For instance, books offer us a relatively more comprehensive summary of English-speaking countries' cultures; and Internet always serves as a convenient means and a broad place to search the cultural knowledge throughout the world.

\section{Pedagogy}

The biggest problem confronting NESTs is that some of them fail to organize their teaching according to their freshmen' English level. Communication between NESTs and their freshmen is a must to understand freshmen' English level, problems and difficulties in EFL learning process. NESTs can also learn from their Chinese counterpart to adjust their teaching methodologies to meet freshmen' needs and expectation. Cooperation between 
NESTs and NNESTs can double freshmen' outcome in EFL learning.

\section{VI.CONCLUSION}

The present study is only an attempt to describe freshmen' evaluation of their NESTs and NNESTs' advantages and disadvantages in their teaching practice. It serves as a pilot study, with many gaps unfilled and much to improve both in extent and depth. Expanding the focus of the study and deepening the understanding of NESTs and NESTs' teaching features are expected in the further research.

\section{ACKNOWLEDGEMENT}

Fund Source: This article is phased research achievements of Hubei Province in 2015 Humanities and Social Sciences Department of Education project "2015Q099 Study of Fossilization in English Vocabulary Teaching on the Analysis of MOODLE."

\section{REFERENCES}

[1] Christophersen, P. \& McArthur, T. 1992. Native speaker [A]. In T. McArthur et al. (eds.). The Oxford companion to the English language [C]. New York: Oxford University Press.

[2] Copieters, R. 1987. Competence difference between native and near-native speakers [J]. Language, 63, 544-73.

[3] Duan P \& Deng L. 2002. Maximizing the expertise of native English Speaking Teachers in Chinese higher education [J]. Teaching English in China, 25(3), 9-13.

[4] Kramsch, C. 1995. The privilege of the non-native speakers. Plenary address at the Annual Convention of Teachers of English to Speakers of Other languages, Long Beach, CA.

[5] Matsuda, A. \& Matsuda, P. K. 2001. Autonomy and collaboration in teacher education: Journal sharing among native and nonnative English-speaking teachers. [J]. The CATESOL Journal, 13(l), 109-121.

[6] Medgyes, P. 1992. Native or nonnative: Who's worth more? [J]. ELT Journal, 46(4). 340-349.

[7] Phillipson, R. 1996. ELT The native speaker's burden [A]. In T. Hedge \& N. Whitney (eds.). Power pedagogy \& practice [C]. Oxford: Oxford University Press. 